\title{
Neurally adjusted ventilatory assist for children on veno-venous ECMO
}

\author{
Jana Assy ${ }^{1,2} \cdot$ Philippe Mauriat $^{1} \cdot$ Nadir Tafer $^{1} \cdot$ Sylvie Soulier ${ }^{1} \cdot$ Issam El Rassi ${ }^{3}$ (I)
}

Received: 18 June 2018 / Accepted: 24 December 2018 / Published online: 4 January 2019

(c) The Japanese Society for Artificial Organs 2019

\begin{abstract}
NAVA may improve veno-venous ECMO weaning in children. This is a retrospective small series, describing for the first time proof-of-principle for the use of NAVA in children on VV ECMO. Six patients (age 1-48 months) needed veno-venous ECMO. Controlled conventional ventilation was replaced with assisted ventilation as soon as lung compliance improved, and could trigger initiation and termination of ventilation. NAVA was then initiated when diaphragmatic electrical activity (EAdi) allowed for triggering. NAVA was possible in all patients. Proportionate to EAdi $(1.8-26 \mu \mathrm{V})$, initial peak inspiratory pressures ranged from 21 to $34 \mathrm{~cm} \mathrm{H}_{2} \mathrm{O}$, and the tidal volume (Vt) from 3 to $7 \mathrm{ml} / \mathrm{kg}$. During weaning, peak pressures increased proportionally to EAdi increase $(5.2-41 \mu \mathrm{V})$, with tidal volumes ranging from 6.6 to $8.6 \mathrm{ml} / \mathrm{kg}$. ECMO was weaned after a median time of 1.75 days on NAVA. Following ECMO weaning, the median duration of mechanical ventilation, and intensive care unit stay were 4.5 days, and 13.5 days, respectively. Survival to hospital discharge was $100 \%$. In conclusion, combining NAVA to ECMO in paediatric respiratory failure is safe and feasible, and may help in a smoother ECMO weaning, since NAVA allows the patient to drive the ventilator and regulate $\mathrm{Vt}$ according to needs.
\end{abstract}

Keywords Extracorporeal membrane oxygenation $\cdot$ ECMO $\cdot$ Veno-venous $\cdot$ ARDS $\cdot$ Ventilatory assist $\cdot$ NAVA

\section{Introduction}

Veno-venous extracorporeal membrane oxygenation (VV ECMO) is now part of the intensive care unit armamentarium for patients with refractory acute respiratory distress syndrome (ARDS), to reduce morbidity, and ventilatorinduced lung injury [1-3]. VV ECMO allows the lungs to rest, while applying protective mechanical ventilation to promote lung recovery [2-4]. There is now a common agreement on the clinical benefits of protective ventilation in adult patients with severe ARDS [5-8]. Protective ventilation $(\mathrm{PV})$ is usually established using assist-controlled

Jana Assy

ja101@aub.edu.lb

Issam El Rassi

issam.rassi@aub.edu.lb

1 Department of Anesthesia and Intensive Care, Hopital HautLévêque, 33604 Pessac, Aquitaine, France

2 Department of Pediatrics, American University of Beirut Medical Center, 11072020 Beirut, Lebanon

3 Department of Surgery, American University of Beirut Medical Center, 11072020 Beirut, Lebanon mechanical ventilation during the initial phase of the disease, under deep sedation and paralysis [9-11]. However, adverse effects of deep sedation and paralysis in the pediatric population are still important concerns, and include bradycardia, ventilator-associated pneumonia, and respiratory muscle atrophy which can occur early after mechanical ventilation, sometimes described as ventilator-induced diaphragmatic dysfunction [9, 12-16]. Allowing for spontaneous breathing as soon as possible has been shown to enhance the distribution of ventilation to dependent lung regions [2, 17], increase systemic blood flow [18], and prevent diaphragmatic dysfunction [16]. Neurally adjusted ventilatory assist (NAVA) is a ventilation mode where the ventilation trigger is the electrical activity of the diaphragm (EAdi), and where the pressure support is proportional to this diaphragmatic activity [19-23]. Case reports [24, 25] have reported the successful addition of NAVA to ECMO during the recovery phase of adults with ARDS. Small series [13] have even tested NAVA during the initial phase of the disease in adults, allowing for a more physiologic protective ventilation. However, NAVA and ECMO have never been previously reported in the pediatric population with severe ARDS. We hypothesized that NAVA would improve 
patient-ventilator synchrony, and improve the ECMO weaning process in children. We hereby report the first experience of NAVA during the recovery phase of ARDS, in a series of 6 consecutive children on VV ECMO.

\section{Methods}

Following IRB approval, we retrospectively analyzed the hospital records of all children who received VV ECMO between July 2014 and June 2016.

ECMO is indicated in our institution according to Extracorporeal Life Support Organization (ELSO) guidelines [26], the recommendations of the "Consensus Conference of the French Intensive Care Society" [7], and the "Pediatric Acute Lung Injury Consensus Conference Group” [5].

\section{ECMO protocol}

All our patients are managed according to institutional VV ECMO protocols, which include the use of a double lumen cannula (Avalon ${ }^{\circledR}$, Maquet, Germany) inserted percutaneously by the intensivist via the right internal jugular vein, under echocardiography guidance. Maquet Rotaflow ${ }^{\circledR}$ centrifugal pump and Maquet's QUADROX- ${ }^{\circledR}{ }^{\circledR}$ oxygenators are used on all patients. ECMO flow is started at more than $60 \%$ of the estimated cardiac output, and then adjusted to maintain arterial oxygen saturation of more than $85 \%$, and mixed venous saturation greater than $60 \%$, estimated by cerebral and peripheral regional oxygen saturation using near-infrared spectroscopy. $\mathrm{FiO}_{2}$ is set initially at $100 \%$, and sweep gas is set at a ratio of $1 / 1$ relative to the ECMO flow, and then modified to maintain normocapnia and normal PH.

\section{Protective mechanical ventilation protocol}

Our protocol for protective MV at the initial phase of the ECMO run follows the below general guidelines on pressure controlled mode:

- Positive end-expiratory pressure $(\mathrm{PEEP})>8 \mathrm{cmH}_{2} \mathrm{O}$

- Peak inspiratory pressure (PIP) $<25 \mathrm{cmH}_{2} \mathrm{O}$

- Tidal volume (Vt) 4-6 ml/kg

- Respiratory rate (RR) between 15 and 30

- $\mathrm{FiO}_{2}<80 \%$

- In case of HFOV: mean pressure (MP) $>12 \mathrm{cmH}_{2} \mathrm{O}$.

PEEP level was carefully chosen under echographic cardiac monitoring and close hemodynamic evaluation to minimize cardiopulmonary interaction. Paralysis was only used at the initial stage of ECMO. Sedation and analgesia were titrated to be as low as possible. Prone positioning
(PP), when indicated, was implemented for 12-18 consecutive h per day.

\section{Assisted ventilation and NAVA settings}

Frequent monitoring of Tidal volume $(\mathrm{Vt})$ changes and repeat evaluation of pulmonary compliance using the pressure-volume curve on the Servo- $\mathrm{I}^{\circledR}$ Maquet (Maquet Critical Care, Rastatt, Germany) ventilators were performed to assess lung status and improvement during ECMO. Improvement usually started with the increase in $\mathrm{Vt}$, using the same PIP and PEEP. Pressure-assisted mode, and then neurally adjusted ventilatory assist (NAVA) mode were instituted as soon as the improvement in $\mathrm{Vt}$ was confirmed. All parents signed the consent for the extra naso-gastric tube electrode necessary for the measurement the diaphragmatic electrical activity (Eadi).

NAVA Eadi inspiratory trigger was set at $0.5-0.8 \mu \mathrm{V}$. Positive end expiratory pressures (PEEP) and $\mathrm{FiO}_{2}$ were not modified, and NAVA levels were initially determined to achieve the same peak inspiratory pressures as in the conventional mode. During the first $30 \mathrm{~min}$, the child was observed closely, and minor adjustments in NAVA levels were performed, based on the respiratory status, to aim for a comfortable respiration with a respiratory rate $\leq 40$ / min. To evaluate the hemodynamic and respiratory impact of NAVA, ECMO parameters (pump flow, sweep gas flow, and $\mathrm{FiO}_{2}$ ) were not modified $3 \mathrm{~h}$ before initiating NAVA, and up to $3 \mathrm{~h}$ after NAVA initiation. The following parameters were analyzed: Heart rate, arterial blood pressure, respiratory rate, peak inspiratory pressure, $\mathrm{pH}, \mathrm{paCO}_{2}$, $\mathrm{paO}_{2}$, oxygen saturation, and tidal volume. The average of the values taken $3 \mathrm{~h}$, then $1 \mathrm{~h}$ before NAVA, were compared with the average of the values measured $1 \mathrm{~h}$ and $3 \mathrm{~h}$ after NAVA initiation.

On conventional, and on NAVA ventilation, nurses were asked to write down all asynchrony episodes, along with their impressions concerning patient-ventilator synchrony. Digital data from the Servo-I ventilators was also used to study asynchrony episodes on NAVA, and to measure and analyze changes in EAdi values.

Comparisons were made using Mann-Whitney $U$ or Pearson tests. $P=0.05$ or less was considered significant. The software used was SPSS (IBM Corp. Released 2016. IBM SPSS Statistics for Windows, Version 24.0. Armonk, NY: IBM Corp.) 


\section{Results}

\section{General ECMO management}

Six patients were treated during this period. The median age was 13.7 months (range 1-48 months). Demographic and pre-ECMO clinical characteristics are shown in Table 1.

All patients had worsening hypoxia under maximal MV settings, with $\mathrm{PaO} 2 / \mathrm{FiO}_{2}$ ratios consistently below 80 , and oxygenation indexes above 40 on $100 \% \mathrm{FiO}_{2}$. In addition, patients 1,2 , and 4 showed high levels of carbon dioxide. Three patients were on high frequency oscillatory ventilation (HFOV). Both drowning patients experienced cardiac arrest before ECMO. Patient 2 had already been ventilated for 7 days before ECMO for severe bronchiolitis.

The sizes of the dual lumen cannulas used were 13 French for the three patients $<4 \mathrm{~kg}$, and 16 French for the three other patients between 10 and $18 \mathrm{~kg}$. There were no complications related to cannula insertion or position.

Table 2 shows the clinical characteristics following ECMO initiation. PH and serum lactates normalized in all patients within a median time of $3.5 \mathrm{~h}$ (range 3-10 h). Inotropic support was necessary in four patients with cardiac dysfunction and aortic velocity time index below $8 \mathrm{~cm} / \mathrm{s}$. Inotropes were initiated before ECMO in all four patients:

Table 1 Demographics, and pre-ECMO clinical characteristics

\begin{tabular}{|c|c|c|c|c|c|c|c|c|c|}
\hline Patient & $\begin{array}{l}\text { Sex } \\
\text { Age } \\
\text { Weight }\end{array}$ & Indication for ECMO & MV (h) & $\mathrm{pH}$ & $\mathrm{PIP}\left(\mathrm{cmH}_{2} \mathrm{O}\right)$ & $\mathrm{PaCO}_{2}$ (torr) & $P / F$ ratio & Prone position & $\begin{array}{l}\text { Lactates } \\
(\mathrm{mmol} / \mathrm{l})\end{array}$ \\
\hline 1 & $\begin{array}{l}\text { Male } \\
5.5 \text { months } \\
3.2 \mathrm{~kg}\end{array}$ & Bronchiolitis & 48 & 7.28 & 32 & 105 & 70 & No & 8.4 \\
\hline 2 & $\begin{array}{l}\text { Male } \\
1 \mathrm{month} \\
3.9 \mathrm{~kg}\end{array}$ & Bronchiolitis & 168 & 7.16 & 30 & 100 & 60 & Yes & 2.7 \\
\hline 3 & $\begin{array}{l}\text { Female } \\
24 \text { months } \\
15 \mathrm{~kg}\end{array}$ & Drowning & 4 & 7.40 & 34 & 30 & 40 & Yes & 7.5 \\
\hline 4 & $\begin{array}{l}\text { Female } \\
22 \text { months } \\
10 \mathrm{~kg}\end{array}$ & Drowning & 8 & 6.79 & $\mathrm{HFO} 30 \mathrm{cmH}_{2} \mathrm{O}$ & 134 & 70 & No & 3 \\
\hline 5 & $\begin{array}{l}\text { Male } \\
48 \text { months } \\
18 \mathrm{~kg}\end{array}$ & Macrophage activation syndrome & 36 & 7.23 & $\mathrm{HFO} 25 \mathrm{cmH}_{2} \mathrm{O}$ & 80 & 60 & Yes & 2.5 \\
\hline 6 & $\begin{array}{l}\text { Female } \\
3.5 \text { months } \\
3.1 \mathrm{~kg}\end{array}$ & Postoperative truncus arteriosus & 24 & 7.25 & HFO $15 \mathrm{cmH}_{2} \mathrm{O}$ & 47 & 40 & Yes & 4.1 \\
\hline
\end{tabular}

ECMO Extracorporeal membrane oxygenator, $H F O$ high frequency oscillator, $M V$ mechanical ventilation, $P I P$ peak inspiratory pressure, $P / F$ ratio $\mathrm{PaO}_{2}$ over inspired oxygen fraction

Table 2 Clinical characteristics and outcome

\begin{tabular}{|c|c|c|c|c|c|c|c|c|}
\hline Patients & Indication for ECMO & ECMO flow $^{\mathrm{a}}$ & ECMO days & $\begin{array}{l}\text { Paraly- } \\
\text { sis } \\
\text { days }\end{array}$ & Inotropes & Dialysis days & Prone days & Outcome \\
\hline 1 & Bronchiolitis & 125 & 12 & 8 & Milrinone & - & - & Discharged alive \\
\hline 2 & Bronchiolitis & 105 & 9 & 4 & - & - & 11 & Discharged alive \\
\hline 3 & Drowning & 85 & 5 & 3 & Epinephrine & 5 & 8 & Discharged alive \\
\hline 4 & Drowning & 105 & 3 & 3 & Epinephrine, milrinone & - & - & Discharged alive \\
\hline 5 & Macrophage activation & 75 & 7 & 1 & - & - & 7 & Discharged alive \\
\hline 6 & $\begin{array}{l}\text { Postoperative truncus } \\
\text { arteriosus }\end{array}$ & 130 & 18 & 3 & $\begin{array}{l}\text { Epinephrine, mil- } \\
\text { rinone, levosimendan }\end{array}$ & 9 & 14 & Discharged alive \\
\hline
\end{tabular}

ECMO Extracorporeal membrane oxygenator

${ }^{\mathrm{a}}$ Flow in $\mathrm{ml} / \mathrm{kg} / \mathrm{min}$ 
In patient 1 , uncontrolled sepsis was complicated by cardiac dysfunction; in patients 3 and 4, drowning was followed by cardiac arrest and cardiac dysfunction; in patient 3 , inotropes were necessary for weaning from cardiopulmonary bypass following cardiac surgery. Two patients needed renal replacement therapy for fluid overload and acute kidney injury.

Median ECMO duration was 8 days (range 3-18 days). Patient 6 had a prolonged ECMO run because of a bacterial lung infection (enterobacter cloacae) on day 5. Following weaning from ECMO, the median duration of mechanical ventilation, and intensive care unit stay were 4.5 days (range 1-8 days), and 13.5 days (range 9-30 days), respectively. Survival to hospital discharge was $100 \%$.

\section{Respiratory management and results}

Paralysis and controlled ventilation were needed in all patients following ECMO initiation for a median time of 3 days (range 1-16 days). There were three patients on HFOV: patients 4 and 5 were put on HFOV in other institutions following resuscitation from drowning; patient 4 was switched to conventional MV immediately following ECMO cannulation, while patient 5 remained on HFOV and ECMO for 48 h. Patient 6 remained on HFOV and ECMO during 15 days. Table 3 shows the ventilation strategies used in each patient, and Fig. 1 shows these strategies on a timeline.

Prone positioning was performed in four patients, and was started early in the course of ECMO, at day 1.7 in average

Table 3 Ventilation strategy before, during, and following ECMO

\begin{tabular}{|c|c|c|c|c|c|c|c|c|c|}
\hline \multirow[t]{2}{*}{ Indication for ECMO } & \multirow{2}{*}{$\begin{array}{l}\text { Ventilation } \\
\text { before ECMO }\end{array}$} & \multirow[t]{2}{*}{ ECMO days } & \multirow{2}{*}{$\begin{array}{l}\text { HFO days } \\
\text { on ECMO }\end{array}$} & \multirow{2}{*}{$\begin{array}{l}\text { CMV days } \\
\text { on ECMO }\end{array}$} & \multicolumn{3}{|l|}{ NAVA days } & \multirow{2}{*}{$\begin{array}{l}\text { MV days } \\
\text { (total) }\end{array}$} & \multirow{2}{*}{$\begin{array}{l}\text { ICU days } \\
\text { after ECMO }\end{array}$} \\
\hline & & & & & On ECMO & After ECMO & Total NAVA & & \\
\hline Bronchiolitis & $48 \mathrm{~h} \mathrm{CMV}$ & 12 & - & 10 & 2 & 1 & 3 & 15 & 16 \\
\hline Bronchiolitis & 7 days MV & 9 & - & 7 & 2 & 2 & 4 & 18 & 11 \\
\hline Drowning & $4 \mathrm{~h} \mathrm{CMV}$ & 5 & - & 4 & 1 & 4 & 5 & 9 & 11 \\
\hline Drowning & $8 \mathrm{~h} \mathrm{HFO}$ & 3 & - & 2 & 1 & 5 & 6 & 8 & 9 \\
\hline Macrophage activation & $36 \mathrm{~h} \mathrm{HFO}$ & 7 & 2 & 4 & 1 & 5 & 6 & 13 & 26 \\
\hline $\begin{array}{l}\text { Postoperative truncus } \\
\text { arteriosus }\end{array}$ & 24 h HFO & 18 & 15 & 1 & 2 & 8 & 10 & 27 & 30 \\
\hline
\end{tabular}

$C M V$ Conventional mechanical ventilation, $E C M O$ extracorporeal membrane oxygenator, $H F O V$ high frequency oscillator ventilation, $I C U$ intensive care unit, $M V$ mechanical ventilation, $N A V A$ neurally adjusted ventilatory assist
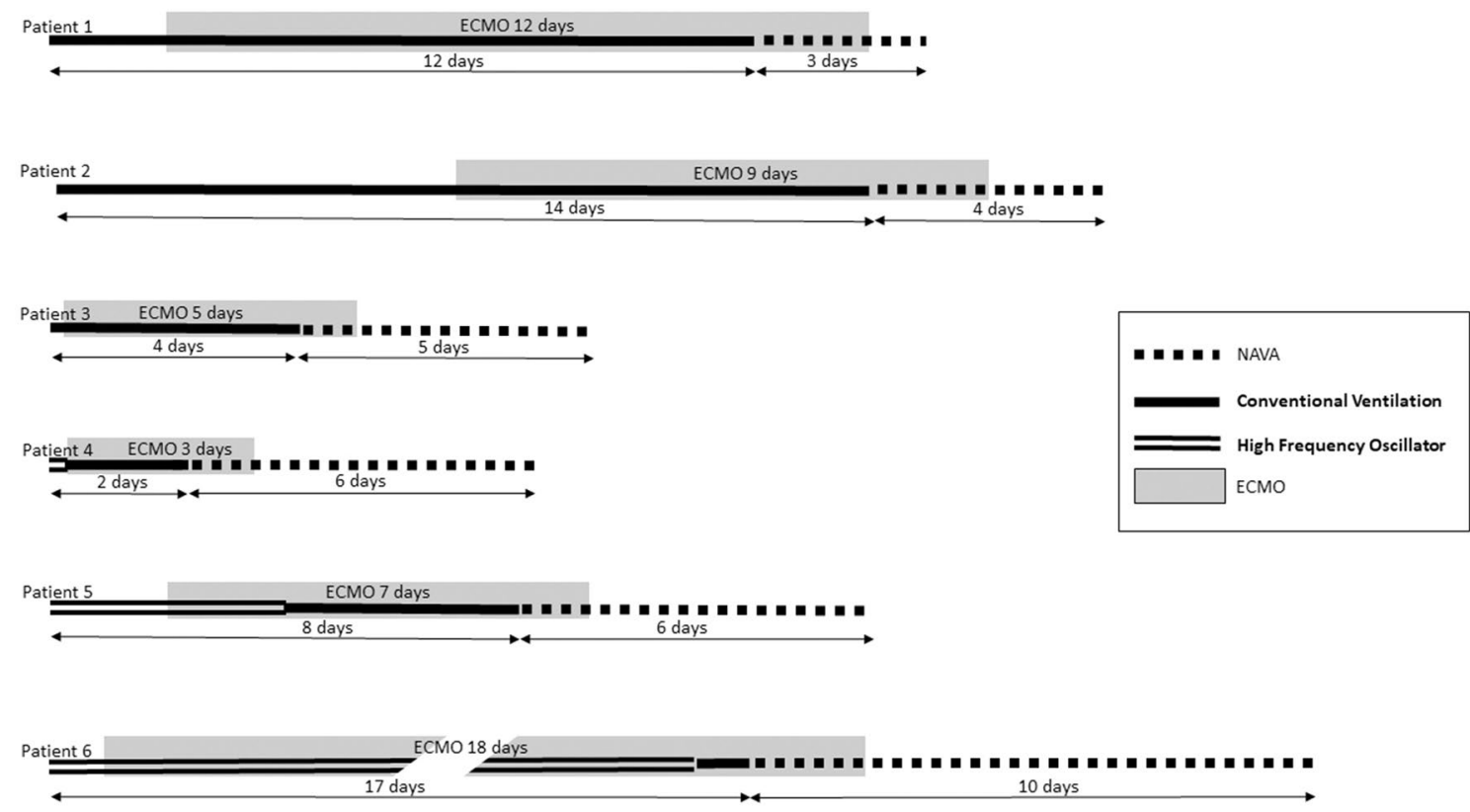

Fig. 1 Different mechanical ventilation strategies and ECMO, shown on a timeline 
(range 0-5 days). Two patients were not proned because of acceptable gas exchange, and the intensivist's preference.

As stated above, controlled conventional MV was replaced with assisted conventional ventilation as soon as lung compliance showed signs of improvement, and changes in flow or pressure could trigger initiation and termination of ventilator support. NAVA was then initiated when diaphragmatic electrical activity (EAdi) allowed for triggering (Table 4): Initial peak Eadi values ranged between 1.8 and $26 \mu \mathrm{V}$. NAVA initiation was possible in all six patients after a median of 6.5 days on ECMO (range 2-15 days).

Heart rate, arterial blood pressure, respiratory rate, peak inspiratory pressure, $\mathrm{pH}, \mathrm{paCO}_{2}, \mathrm{paO}_{2}$, oxygen saturation, and tidal volume, were compared on conventional ventilation, and then on NAVA, under unchanged ECMO parameters. Values and interquartile range are shown in Table 4: all six patients remained stable, and there were no statistically significant modification of any of the parameters before and after NAVA, despite less sedation.

Patient-ventilator synchrony was improved in all six patients. Analysis of the diaphragmatic electrical activity of the six patients showed that patient-ventilator asynchrony episodes occurred in less than $10 \%$ of all NAVA ventilation cycles, and most were triggering asynchronies. Analysis of the nurses' notes of the patients' charts showed that most of these asynchrony episodes were due to complete or partial loss of the EAdi signal caused by agitation because of secretions. The patients could be calmed down and synchronized again with the ventilator following tracheal suctioning, and proper repositioning of the NAVA esophageal sensor.

Before NAVA initiation, these dyssynchrony episodes were much more frequent according to our observations, and to nurses' notes. However, the prevalence of these episodes could not be appreciated objectively, because of the absence of digital or paper data from the conventional ventilator. In contrast to NAVA, however, during most asynchrony episodes on conventional ventilation, there was no evidence of tracheobronchial secretions, and asynchrony was treated either by fine-tuning the respirator settings, or with sedation.

\section{ECMO weaning}

ECMO was weaned before any attempt at extubation, after a median time of 1.75 days (range 1-2 days) on NAVA. Following the decrease of sweep gas flow by $50 \%$ on the ECMO membrane, all patients kept a stable $\mathrm{PCO} 2$ and $\mathrm{PH}$ by increasing the peak EAdi to values ranging from 5.2 to $41 \mu \mathrm{V}$, thus increasing proportionately the peak inspiratory pressure to values ranging from 22 to $38 \mathrm{cmH}_{2} \mathrm{O}$, and subsequently tidal volumes to more than $6.6 \mathrm{ml} / \mathrm{kg}(6.6-8.6 \mathrm{ml} /$ $\mathrm{kg}$ ) (Table 5). The increase in tidal volume ranged from a modest $8 \%$ and $12 \%$ in patients 1 and 2 , to a spectacular $88 \%$ in patient 6 , associated with $72-80 \%$ reduction in respiratory rate in all patients. The increase in tidal volume, or decrease in respiratory rate were not proportional to EAdi increase, with $p$ values of 0.13 and 0.72 , respectively (Table 5).

Any decrease in $\mathrm{PaO}_{2}$ was compensated by increasing the $\mathrm{FiO}_{2}$ on the ventilator.

\section{Discussion}

This is the first study combining NAVA and VV ECMO in clinical practice in a pediatric population with severe respiratory failure. This series only aims to report the proofof-concept, and describe the clinical management of these patients, without drawing any conclusions concerning outcomes, due to the small number of patients.
Table 4 Comparison of hemodynamic and respiratory parameters before and after NAVA initiation

\begin{tabular}{llllll}
\hline & $\begin{array}{l}{[\mathrm{H}-1+\mathrm{H}-3]} \\
\text { before NAVA }\end{array}$ & Inter-quartile range & $\begin{array}{l}{[\mathrm{H} 1+\mathrm{H} 3]} \\
\text { after NAVA }\end{array}$ & Inter-quartile range & $p$ \\
& 128 & {$[121.0-134.4]$} & 130 & {$[129.0-134.4]$} & 0.81 \\
$\begin{array}{l}\text { Heart rate (per min) } \\
\text { Blood pressure }\end{array}$ & & & & & \\
$\quad$ Systolic (mmHg) & 94.9 & {$[82.9-103.5]$} & 93.8 & {$[87.0-98.1]$} & 0.82 \\
$\quad$ Diastolic (mmHg) & 51.3 & {$[43.5-58.8]$} & 51.5 & {$[41.1-56.0]$} & 0.99 \\
$\quad$ Mean (mmHg) & 70.8 & {$[59.9-79.0]$} & 69.6 & {$[60.0-74.4]$} & 0.70 \\
Respiratory rate (per min) & 46 & {$[36.8-57.6]$} & 46 & {$[35-54]$} & 0.94 \\
Peak pressure (mmH $\left.{ }_{2} \mathrm{O}\right)$ & 15 & {$[12.3-17.5]$} & 13 & {$[11.6-14.5]$} & 0.23 \\
Tidal volume (ml) & 6.76 & {$[5.35-7.93]$} & 6.17 & {$[4.76-7.10]$} & 0.48 \\
$\mathrm{pH}^{\mathrm{PaCO}}$ (mmHg) & 7.40 & {$[7.39-7.45]$} & 7.39 & {$[7.34-7.41]$} & 0.94 \\
$\mathrm{PaO}_{2}$ (mmHg) & 45.3 & {$[40.05-47.6]$} & 46.2 & {$[41.7-49.5]$} & 0.99 \\
$\mathrm{SaO}_{2}$ & 106.5 & {$[80.5-133.5]$} & 117.2 & {$[80.4-149.1]$} & 0.70 \\
\hline
\end{tabular}

NAVA Neurally adjusted ventilatory assist, $\mathrm{PaCO}_{2}$ arterial content in carbon dioxyde, $\mathrm{PaO}_{2}$ arterial content in oxygen, $\mathrm{SaO}_{2}$ arterial oxygen saturation 
Table 5 Changes in diaphragmatic electrical activity, tidal volume, and respiratory rate, before and after the beginning of ECMO weaning

\begin{tabular}{|c|c|c|c|c|c|c|}
\hline \multirow[t]{2}{*}{ Patients } & \multicolumn{3}{|c|}{ Before ECMO weaning } & \multicolumn{3}{|c|}{$\begin{array}{l}\text { During ECMO weaning ( } 3 \mathrm{~h} \text { after weaning } \\
\text { initiation: } 50 \% \text { reduction in sweep gas) }\end{array}$} \\
\hline & $\begin{array}{l}\text { Mean } \\
\text { EAdi } \\
(\mathrm{mV})\end{array}$ & $\mathrm{RR}$ & $\mathrm{Vt}(\mathrm{ml} / \mathrm{kg})$ & $\begin{array}{l}\text { EAdi }(\mathrm{mV}) \\
(\% \text { increase })\end{array}$ & $\mathrm{RR}(\% \text { decrease })^{\mathrm{a}}$ & $\begin{array}{l}\mathrm{Vt}(\mathrm{ml} / \\
\mathrm{kg})(\% \\
\text { increase })^{\mathrm{b}}\end{array}$ \\
\hline Bronchiolitis & 5.5 & 48 & 7.2 & $16(190 \%)$ & $35(72 \%)$ & $7.7(8 \%)$ \\
\hline Bronchiolitis & 8.1 & 53 & 7.1 & $28(245 \%)$ & $42(79 \%)$ & $7.9(12 \%)$ \\
\hline Drowning & 26 & 46 & 5.1 & $41(57 \%)$ & $35(76 \%)$ & $6.6(30 \%)$ \\
\hline Drowning & 15 & 38 & 6.3 & $22(46 \%)$ & $30(78 \%)$ & $8.1(29 \%)$ \\
\hline Macrophage activation & 12.4 & 36 & 4.6 & $18(45 \%)$ & $28(77 \%)$ & $8.6(88 \%)$ \\
\hline Postoperative truncus & 1.8 & 55 & 6.2 & $5.2(188 \%)$ & $44(80 \%)$ & $7.5(22 \%)$ \\
\hline
\end{tabular}

$E A d i$ Electrical activity of the diaphragm, $R R$ respiratory rate, $V t$ tidal volume

${ }^{a}$ No significant relation with EAdi $(p=0.72)$

${ }^{\mathrm{b}}$ No significant relation with EAdi $(p=0.13)$
The management of mechanical ventilation on ECMO remains a matter of debate. The focus remains on lung rest, and the best approach to provide this while preventing further lung injury has not been convincingly determined [3, 8]. Protective ventilation has been advocated as one of the major factors for improving lung function on ECMO [2, 9, 13]. A Canadian team conducted an international survey to describe ventilation practices for patients on VV ECMO in ELSO registered centers [27]. In the neonatal and pediatric population, $47 \%$ of the centers used protective $\mathrm{Vt}(4-6 \mathrm{ml} /$ $\mathrm{kg}$ ), and $28 \%$ used ultra-protective $\mathrm{Vt}(<4 \mathrm{ml} / \mathrm{kg}$ ). Only $11 \%$ of these centers targeted high PEEP levels $\left(11-15 \mathrm{cmH}_{2} 0\right)$, whereas $65 \%$ used PEEP levels between 6 and $10 \mathrm{cmH}_{2} 0$. Controlled modes of mechanical ventilation were the most commonly used modes during the initial phase of the disease among all centers.

Controlled ventilation is recommended, and usually necessary in current practice, under deep sedation, during the early phases of severe ARDS when lung function and compliance are greatly compromised [11]. Under VV ECMO, controlled ventilation and deep sedation allow the patient to benefit fully from protective, or ultra-protective ventilation settings, by reliably controlling the tidal volume and peak pressures. In addition, pressure-controlled ventilation mode allows for daily monitoring of progressive increase in the $\mathrm{Vt}$, signaling lung function improvement.

As soon as lung improvement is translated clinically into an increase in $\mathrm{Vt}$, spontaneous breathing may be initiated by decreasing sedation and resorting to assisted ventilation. Spontaneous breathing carries several benefits in critically ill patients; it is essential to prevent diaphragm and respiratory muscle atrophy, which may occur sometimes as early as $18 \mathrm{~h}$ after mechanical ventilation [12]. Assisted ventilation modes can also decrease days on mechanical ventilation, and length of stay in the intensive care unit [27-29]. Furthermore, allowing spontaneous breathing during ECMO was associated with redistribution of ventilation towards dorsal areas, reducing atelectasis and intrapulmonary shunts [30]. Another benefit of spontaneous breathing was demonstrated by Hering et al. [31]: Visceral organ perfusion, an important determinant of outcome in critically ill patients, was shown to increase with the initiation of spontaneous breathing.

However, conventional pressure support ventilation may be difficult to implement in ARDS patients with low lung compliance; trigger delay may cause late initiation, or early termination of mechanical support [32]. This is clinically translated into irregular, disturbed respiration, leading to insufficient respiratory support, putting the patients at high risk further iatrogenic lung injury [33]. One of the major advantages of NAVA over other modes of assisted ventilation, is improved patient-ventilator synchrony [34, 35]. NAVA is immediately triggered by the electrical signal from the spontaneous diaphragmatic contraction, and the pressure support is proportional to the EAdi [13]. The patient can thus regulate his ventilation by varying his respiratory rate, and his diaphragmatic contraction, which will control the $\mathrm{Vt}$ and peak pressure. Hence, the incidence of asynchronies, in terms of premature cycling, ineffective triggering, double or auto-triggering, is decreased in most reports, compared to conventional pressure support ventilation [25, 35]. Following NAVA initiation, the improvement in patient-ventilator synchrony was obvious clinically in this small series of patients we report herein. We did not compare asynchrony on conventional, then on NAVA ventilation, because the incidence of asynchrony under conventional pressure support ventilation was not measured objectively. The accepted standard for the detection of asynchrony includes measurement of esophageal pressure (with a balloon), and/or electrical activity of the respiratory muscles (eg, diaphragm, transverse abdominis) [36]. These techniques allow for definitive confirmation of respiratory muscle activity and allow precise determination of neural inspiratory and expiratory time; 
detection of asynchrony using only ventilator waveform analysis, may lead to underestimation or overestimation of the amount of asynchrony, whereas on NAVA, the detection and analysis of asynchrony are enhanced with EAdi measurements provided by the esophageal probe. Despite less sedation, an obvious reduction in asynchrony episodes was observed. Furthermore, NAVA initiation did not affect any of the hemodynamic or respiratory parameters measured in this series, which suggests that NAVA may be considered as a safe alternative in this fragile subpopulation of patients. A comparison of patient-ventilator interaction was conducted by Mauri et al. in a series of adult patients on VV ECMO [25]: they concluded that asynchrony is definitely reduced with NAVA, and that in patients with very low lung compliance, NAVA may be the most appropriate way to initiate assisted ventilation.

In addition to offering the patient the possibility to adapt, and drive the ventilator, NAVA proportional pressure support allows the patient to regulate $\mathrm{Vt}$ according to his physiological needs. We witnessed this clinically in our pediatric patients who progressively increased their Vt during ECMO weaning; however, The increase in tidal volume, though significant, was not found proportional to the increase in EAdi values in our series, a finding that may be explained by patient-specific factors, and the heterogenous origin of lung injury with abnormal lung compliance due to residual lung disease. This beneficial patient-ventilator interaction was shown also in the elegant study of Karagiannidis in six adults on VV ECMO for severe ARDS [13]: during the weaning of ECMO, the progressive decrease in sweep gas was compensated by a stepwise increase in $\mathrm{Vt}$ and a pronounced increase in respiratory rate. The patients chose the best possible protective ventilation, by increasing the minute volume, while keeping the $\mathrm{Vt}$ around $6 \mathrm{ml} / \mathrm{kg}$ [13]. This is partly explained by the fact that NAVA automatically adjusts the level of pressure support, to the magnitude of inspirational effort, reducing the possibility of overassistance and the development of unnecessary high tidal volumes [32, 36, 37]. According to Karagiannidis, the drive for the needed EAdi, and thus the optimal minute ventilation is not oxygenation, but carbon dioxide and $\mathrm{PH}$ values. This was demonstrated by Kolobow and colleagues [38] in lambs on ECMO: the central drive for the rapid changes in spontaneous ventilation following the weaning of ECMO, depended on $\mathrm{CO}_{2}$ extraction by the ECMO membrane. Similar findings were reported by Brander et al. [39], who demonstrated the same preferential up-regulation in the respiratory rate in rabbits on NAVA for acute lung injury.

This study has several limitations, including its retrospective design and the limited patient number. It is a small case series without historical controls, or dedicated measurement of the nominal purpose of NAVA, i.e. to decrease asynchrony and diaphragm atrophy. Subjective provider assessment of patient ventilator synchrony by nurses or physicians should not be an acceptable end point, but cannot be completely discredited, especially due to the potential bias of knowing that NAVA improves patient ventilator synchrony, and the inability to blind which patients are on NAVA.

In conclusion, this strategy of combining NAVA to ECMO in severe paediatric respiratory failure has shown to be safe and successful. The simultaneous use of NAVA and ECMO in adult has also been successfully reported. Further studies with larger cohorts are needed to establish a consensus and to guide practice regarding optimal protective ventilation strategies during pediatric VV ECMO.

Funding None.

\section{Compliance with ethical standards}

Conflict of interest The authors declare that they have no conflict of interest.

\section{References}

1. Peek GJ, Mugford M, Tiruvoipati R, et al. Efficacy and economic assessment of conventional ventilator support versus extracorporeal membrane oxygenation for severe adult respiratory failure (CESAR): a multicenter randomized controlled trial. Lancet. 2009;374:1351-63.

2. Schmidt M, Pellegrino V, Coombes A, et al. Mechanical ventilation during membrane oxygenation. Crit Care. 2014;18:203-10.

3. Maslach-Hubbard A, Bratton SL. Extracorporeal membrane oxygenation for pediatric respiratory failure: history, development and current status. World J Crit Care Med. 2013;2:29-39.

4. Schmidt M, Steart C, Bailey M, et al. Mechanical ventilation management during extracorporeal membrane oxygenation for acute respiratory distress syndrome: a retrospective international multicenter study. Crit Care Med. 2015;43:654-64.

5. Pediatric Acute Lung Injury Consensus Conference Group. Pediatic acute respiratory distress syndrome: consensus recommendation from the pediatric acute lung injury consensus conference. Pediatr Crit Care. 2015;16:428-439.

6. Kneyber M, Jouvet P, Rimensberger P. How to manage ventilation in pediatric acute respiratory distress syndrome. Intensive Care Med. 2014;40:1924-6.

7. Richard C, Argaud L, Blet A, et al. Extracorporeal life support for patients with acute respiratory distress syndrome (adult and paediatric). Consensus conference organized by the French Intensive Care Society. Rev Mal Respir. 2014;31:779-795.

8. Huh JW. Update on the extracorporeal life support. Tuberc Resp Dis. 2015;78:149-55.

9. Zhang Z, Gu WJ, Chen K, et al. Mechanical ventilation during extracorporeal membrane oxygenation in patients with acute severe respiratory failure. Can Respir J 2017. https://doi. org/10.1155/2017/1783857. (Epub 2017).

10. Papazian L, Forel JM, Gacouin A, et al. Neuromuscular blockers in early acute respiratory distress syndrome. N Engl J Med. 2010;363:1107-16.

11. Forel JM, Roch A, Marin V, et al. Neuromuscular blocking agents decrease inflammatory response in patients presenting 
with acute respiratory distress syndrome. Critical Care Med. 2006;34:2749-57.

12. Powers SK, Kavazis AN, Levine S. Prolonged mechanical ventilation alters diaphragmatic structure and function. Crit Care Med. 2009;37:347-53.

13. Karagiannidis C, Lubnow M, Philipp A, et al. Autoregulation of ventilation with neurally adjusted ventilatory assist on extracorporeal lung support. Intensive Care Med. 2010;36:2038-44.

14. Levine S, Nguyen T, Taylor N, et al. Rapid disuse atrophy of diaphragm fibers in mechanically ventilated humans. N Engl J Med. 2008;358:1327-35.

15. Vassilakopoulos T, Zakynthinos S, Roussos C. Bench-to-bedside review: weaning failure-should we rest the respiratory muscles with controlled mechanical ventilation? Crit Care. 2006;10:204-9.

16. Schweickert WD, Pohlman MC, Pohlman AS, et al. Early physical and occupational therapy in mechanically ventilated, critically ill patients: a randomised controlled trial. Lancet. 2009;373:1874-82.

17. Yoshida T, Rinka H, Kaji A, et al. The impact of spontaneous ventilation on distribution of lung aeration in patients with acute respiratory distress syndrome: airway pressure release ventilation versus pressure support ventilation. Anesth Analg. 2009;109:1892-900.

18. Putensen C, Mutz NJ, Putensen-Himmer G, et al. Spontaneous breathing during ventilatory support improves ventilation-perfusion distributions in patients with acute respiratory distress syndrome. Am J Respir Crit Care Med. 1999;159:1241-8.

19. Sinderby C. Ventilatory assist driven by patient demand. Am J Respir Crit Care Med. 2003;168:720-30.

20. Lellouche F, Brochard L. Advanced closed loops during mechanical ventilation (PAV, NAVA, ASV, SmartCare). Best Pract Res Clin Anaesthesiol. 2009;23:81-93.

21. Beck J, Reilly M, Grasselli G, et al. Patient-ventilator interaction during neurally adjusted ventilatory assist in very low birth weight infants. Pediatr Res. 2009;65:663-8.

22. Barwing J, Ambold M, Linden N, et al. Evaluation of the catheter positioning for neurally adjusted ventilatory assist. Intensive Care Med. 2009;35:1809-14.

23. Colombo D, Cammarota G, Bergamaschi V, et al. Physiologic response to varying levels of pressure support and neurally adjusted ventilatory assist in patients with acute respiratory failure. Intensive Care Med. 2008;34:2010-8.

24. Bein T, Osborn E, Hofmann HS, et al. Successful treatment of a severely injured soldier from Afghanistan with pumpless extracorporeal lung assist and neurally adjusted ventilatory support. Int J Emerg Med. 2010;3:177-9.

25. Mauri T, Bellani G, Grasselli G, et al. Patient-ventilator interaction in ARDS patients with extremely low compliance undergoing ECMO: a novel approach based on diaphragm electrical activity. Intensive Care Med. 2013;39:282-91.

26. Brogan T, Lequier L, Lorusso R, MacLaren G, Peek G. ECMO: extracorporeal cardiopulmonary support in critical care, Red book. 5th ed. Ann Arbor: Extracorporeal Life Support Organization; 2017.

27. Putensen C, Hering R, Muders T, et al. Assisted breathing is better in acute respiratory failure. Curr Opin Crit Care. 2005;11:63-8.

28. Putensen C, Zech S, Wrigge H, et al. Long-term effects of spontaneous breathing during ventilatory support in patients with acute lung injury. Am J Respir Crit Care Med. 2001;164:43-9.

29. Esteban A, Frutos F, Tobin MJ, et al. A comparison of four methods of weaning patients from mechanical ventilation. Spanish Lung Failure Collaborative Group. N Engl J Med. 1995;332:345-50.

30. Güldner A, Kiss T, Bluth T, et al. Effects of ultraprotective ventilation, extracorporeal carbon dioxide removal, and spontaneous breathing on lung morphofunction and inflammation in experimental severe acute respiratory distress syndrome. Anesthesiology. 2015;122:631-46.

31. Hering R, Bolten JC, Kreyer S, et al. Spontaneous breathing during airway pressure release ventilation in experimental lung injury: effects on hepatic blood flow. Intensive Care Med. 2008;34:523-7.

32. Goto Y, Katayama S, Shono A, Mori Y, Miyazaki Y, Sato Y, Ozaki M, Kotani T. Roles of NAVA in improving gaz exchange in a severe acute respiratory distress syndrome patient after weaning from ECMO: a case report. J Intensive Care. 2016;4:21-31.

33. De Wit M, Miller KB, Green DA, et al. Ineffective triggering predicts increased duration of mechanical ventilation. Crit Care Med. 2009;37:2740-5.

34. Richard JC, Lefebvre JC, Tassaux D, et al. Update in mechanical ventilation 2010. Am J Respir Crit Care Med. 2011;184:32-6.

35. Piquilloud L, Vignaux L, Bialais E, et al. Neurally adjusted ventilatory assist improves patient-ventilator interaction. Intensive Care Med. 2011;37:263-71.

36. Epstein SK. How often does patient-ventilator asynchrony occur and what are the consequences? Respir Care. 2011;56:25-35.

37. Di Mussi R, Spadaro S, Mirabella L, et al. Impact of prolonged assisted ventilation on diaphragmatic efficiency; NAVA versus PSV. Crit Care. 2016;20:1-12.

38. Kolobow T, Gattinoni L, Tomlinson TA, et al. Control of breathing using an extracorporeal membrane lung. Anesthesiology. 1977;46:138-41.

39. Brander L, Sinderby C, Lecomte F, et al. Neurally adjusted ventilatory assist decreases ventilator-induced lung injury and nonpulmonary organ dysfunction in rabbits with acute lung injury. Intensive Care Med. 2009;35:1979-89.

Publisher's Note Springer Nature remains neutral with regard to jurisdictional claims in published maps and institutional affiliations. 